\title{
LA ABUNDANCIA DEL MALESTAR
}

\author{
Nibaldo Fabrizio Mosciatti
}




\section{NIBALDO FABRIZIO MOSCIATTI}

Periodista de la Pontificia Universidad Católica. Trabajó de reportero en Radio Chilena, redactor político de la revista Apsi (de 1986 a 1991), trabajó en el programa El Mirador de TVN, y desde 1997 trabaja en la Radio Bío Bío, en Santiago, en donde es jefe de prensa. Columnista de algunos medios y escritor del libro Lautaro, Halcón Veloz, editado por Amanuta. 


\section{LA ABUNDANCIA DEL MALESTAR}

Como nunca, el panorama de la política nacional juega a la esquizofrenia: las loas al desarrollo del país -particularmente medido desde una perspectiva exclusivamente económica, que tiene un correlato social en el vuelco hacia el consumo- conviven con un malestar subterráneo y sordo. Esto se expresa en malos humores, depresiones (y las consiguientes automedicaciones), resentimiento larvado y la sensación que, permanentemente, algún poder -o los poderes, todos ellos- está abusando con cada uno de los que se siente parte de la plebe; o sea, de la mayoría abrumadora de Chile.

Será, tal vez, porque también nunca, en virtud de la concentración económica, entre otras concentraciones, se tuvo con tanta certeza la sensación de que "allá arriba" un grupo pequeño, un club, con lazos múltiples entre sus miembros, es el que rige los destinos del país. O sea, que la democracia es formalmente incuestionable, pero no ha sido capaz de cumplir con uno de sus objetivos fundamentales: desconcentrar el poder, repartirlo, democratizarlo. Por lo tanto, democracia a medias: formal, pero no sustantiva.

Esto no es nuevo. Nada tiene que ver con que esté gobernando una coalición de derecha, encabezada por un ciudadano que, al menos públicamente, es de los menos simpáticos, y que carga con la imagen de ser expresión del poder económico, el poder donde hoy se concentra el poder.

Lo que ocurre es que durante 20 largos años -los de los gobiernos de la Concertación de Partidos por la Democracia, que no por nada terminó en simple Concertaciónla coalición de gobierno se benefició de un chantaje sobre ese porcentaje de la ciudadanía que a fines de los años 1980 se decantó como antidictatorial y, por extensión, en antiderecha. Porque la derecha en Chile nunca fue capaz, en los 70, 80, 90 y hasta en los inicios del actual siglo, de distanciarse de Augusto Pinochet y su dictadura, ya que era-sinceremos un poco las cosas- pinochetista y dictatorial.

(Tanto lo fue, que señeras figuras de ese sector, como Hugo Zepeda Barrios y Julio Subercaseaux Barros, parlamentarios del Partido Nacional, fueron despreciados y hasta expulsados de los círculos sociales que frecuentaban, simplemente por ser consecuentes con su discurso opositor a la Unidad Popular, basado en la defensa de las libertades democráticas. Como de verdad creían en esas libertades, también las defendieron durante la dictadura militar. El resto de la derecha, no. Partiendo por Jaime Guzmán, impecable orador a favor de las libertades bajo la UP, pero activo defensor de la dictadura, de la inevitabilidad de sus atrocidades y, por lo tanto, cómplice y/o encubridor de las mismas. Habría que rescatar a esas figuras escasísimas, como Zepeda y Subercaseaux, porque son el único, frágil y delgado hilo que nos remite a la existencia, hace 40 años, de una derecha republicana.).

Cuando la derecha se distanció de la dictadura, al menos discursiva y simbólicamente -soy un convencido que no emocionalmente: por algo muchos de sus próceres 
atesoran, hoy, las fotos en las que aparecen con el dictador-, pudo ganar una elección presidencial.

\section{CHANTAJE Y VETO}

El chantaje de la Concertación funcionó de manera maniquea, como es la mejor forma en que operan esas pulsaciones políticas colectivas: vote por la Concertación, que solo ella es la que garantiza la democracia; acepte todo lo que haga la Concertación, porque si se opone puede provocar la caída de esa coalición y, por extensión, de la garantía del régimen democrático; no critique, porque eso es hacerle el juego a la derecha, a los antidemocráticos, a los pinochetistas.

Nunca antes un gobierno tuvo ese poder; el poder de acallar buena parte de la crítica por lo que decía representar, por lo que decía resguardar, por lo que decía garantizar. Silenciar incluso los reparos de quienes lo apoyaban y, por lo tanto, impedir lo que pudo ser una crítica constructiva.

Y es que se olvida que cuando la ciudadanía ganó en el plebiscito de 1988 y en las elecciones de 1989, lo hizo convencida de que su triunfo implicaba el desmantelamiento de aspectos sustanciales del modelo impuesto por la dictadura. La Concertación no lo hizo, pero tampoco lo intentó, al menos con la convicción y fuerza que se esperaba.

La Concertación tiene un argumento de peso para justificar esa renuncia -la renuncia a llevar adelante lo que sus electores pedían-: que la derecha, primero a través de los senadores designados, y, luego, con el empate eterno que garantiza el sistema electoral binominal, impidió tramposamente la conformación de una mayoría en el Congreso suficiente para realizar esos cambios. Es lo que el ex presidente Ricardo Lagos ha definido como el "veto" ejercido por la derecha. Pero los vetos están para denunciarlos, combatirlos, derribarlos. En eso la Concertación fue, a lo menos, feble. La derecha -o sea, el actual gobierno o muchos de los que son figuras del actual gobierno- usó y abusó de esos vetos, sumando pequeñas ventajas, aunque fuese al costo de reafirmar, así, su esencia antidemocrática.

La llegada de la derecha al poder (al poder político, ya que del verdadero poder, el económico, que hoy supera a la política, nunca se fue) es, en cierta forma, el certificado de madurez y legitimidad de la democracia chilena. Sin chantaje, sin autocensura. Sin miedo a la alternancia. Y, por lo tanto, con espacio para la crítica y la desafección.

Eso es lo que vive y sufre el gobierno de Sebastián Piñera. La inédita extensión del universo de las opiniones y los juicios, sin bálsamos ni disimulos.

Pero, además, experimenta la extensión de una crítica donde muchos de quienes hoy reclaman lo hacen también por lo que hicieron o dejaron de hacer los gobiernos anteriores -gobiernos a los que adhirieron- y que, ahora, sin ese chantaje al que se sometieron, se sienten en libertad de reprochar. Sí, el gobierno es otro, pero no importa, porque encarna las políticas que, chantaje mediante, la Concertación hizo tragar a más de alguno de sus votantes. Y, además, este gobierno es el que mejor encarna a los creadores y sostenedores del actual modelo socioeconómico. 
Ese nuevo escenario es, al mismo tiempo, el reflejo de que la particular transición chilena -timorata y conservadora- generó un sistema político, o de representación política, crecientemente distante de la ciudadanía. Un ejemplo de esto, que debió haberse visto como una alerta, fue la dificultad para aprobar una ley de divorcio que, desde hacía muchos años, la ciudadanía reclamaba.

\section{LA TRANSICIÓN CENSURADA O REPRIMIDA}

El año clave para la transición no fue ni 1988, el del triunfo del NO en el plebiscito y la consiguiente derrota del régimen pinochetista, ni 1990, con la instalación de Patricio Aylwin en La Moneda. Fue 1989, ese año sui géneris, en el que un dictador derrotado permaneció en el poder sin que los ganadores intentaran recortarle algo de sus poderes (por ejemplo, insólitamente, a pesar del rol de la franja televisiva en el triunfo del NO, a la Concertación no se le ocurrió -bueno, probablemente se le ocurrió, lo que hace el asunto más grave- exigir una hora diaria en Televisión Nacional de Chile). Ese fue el año de la negociación y, fundamentalmente, de la desmovilización ciudadana.

Probablemente la desmovilización fue la primera carta ofrecida en esa negociación.

La mayoría de los miembros de la Concertación, como casi todos los que se encumbran en el poder, olvidaron su origen y su génesis. No solo sociales, sino también de la fuerza que los llevó al triunfo de 1988. Esa fuerza no surgió ni de los partidos, ni de las alianzas, ni del respaldo de la Iglesia Católica, ni de la ayuda exterior, sino de la movilización de la ciudadanía. Esa energía que, desde las protestas, venció al miedo y, como consecuencia de ello, se activó, logrando la recuperación de la democracia.

La primera y más simbólica medida de la Concertación, inmediatamente después del plebiscito de 1988, fue cerrar las Casas del NO que, en casi todas las comunas, eran centro de activismo, reunión y debate. Sobre todo eso último, el debate, era lo que los dirigentes de la Concertación querían evitar. Y lo lograron.

La desactivación de la movilización social, justificada bajo el argumento de la responsabilidad para construir una transición pacífica y estable, generó un espacio sin discusión y, por consiguiente, sin críticas ni elaboración de ideas. Un síntoma de aquello fue la desaparición de los medios opositores a la dictadura, eventuales "Pepes Grillos" de la Concertación, en cuanto a ser memoriosos de lo que esa coalición prometió como programa de gobierno. El efecto fue doble: no solo se inhibió el debate, sino que se facilitó el que la Concertación asumiera políticas que había denostado y, además, renunciara a una serie de promesas que habían sido la exigencia de los movilizados que la habían colocado en el poder. Escojamos un símbolo de esa transformación camaleónica: Edgardo Boeninger, no por nada elevado en figura señera del altar de la transición. Si la dictadura postulaba una "democracia protegida", la Concertación construyó, a su vez, una "transición protegida”. Ambas, ¿̇protegidas de qué? La respuesta es simple: de la soberanía popular.

Si no había otra alternativa de transición -cosa que, ahora, argumentan varios de esos funcionarios gubernamentales-, no se sintieron con la obligación de explicarlo porque, además, no hubo espacio para la exigencia de explicaciones. La ciudadanía 
desmovilizada y acallada siempre es algo cómodo. El problema, y ahora es cuando lo lamentan, al menos por cálculos electoralistas, es que esa ciudadanía acallada y desmovilizada también se aleja. Y deja de quererte. Hoy, en los hechos, la Concertación no existe. Por un dato obvio: nadie (o demasiado pocos) la echa de menos.

\section{EL OLVIDO DE LA GENTE (ESO QUE LLAMABAN EL PUEBLO)}

Ese diseño de la transición, al que, evidentemente, no fue ajena la amenaza de los militares (en todo caso, exagerada por la Concertación; tal vez como mecanismo inconsciente para justificar las renuncias que estaba aceptando) y la presión del empresariado, terminó, en la práctica, con el olvido de la gente, eso que, alguna vez, llamaban El Pueblo. Por de pronto, el término dejó de usarse. ¿Pudor? ¿Vergüenza? ¿Reconocimiento de las renuncias, de lo entregado, de lo traicionado?

La política es cosa práctica. O, mejor dicho, si deja de ser práctica corre el riesgo de transformarse en derrota. Pero no hay que mirarlo todo desde esa óptica, porque lo práctico puede terminar siendo solo cálculo, dividendo corto, renuncia a elaborar proyectos y, obviamente, a proyectarse. No nos detendremos, entonces, en lo mucho de bien que hizo la Concertación, porque estamos analizando el proceso político que terminó vaciando de contenido -y, por qué no, de "alma"- a la coalición estadísticamente más exitosa de la historia de Chile. Y, de paso, poniendo en peligro a la propia democracia al vaciarla, a su vez, de contenido.

Al fin de cuentas, muchos individuos con espíritu crítico terminaron respaldando incondicionalmente a los gobiernos concertacionistas -alguna vez habrá que analizar el rol acomodaticio y sumiso de aquellos que podrían ser calificados de "intelectuales"-, lo que, sumado a la desmovilización popular, tuvo como obvia consecuencia el alejamiento de esa coalición y sus gobiernos, de la ciudadanía. Un buen ejemplo de ello fue el decaimiento de la actividad de los partidos políticos.

No es que no votara, esa ciudadanía, finalmente, por la Concertación. El problema es que un buen porcentaje de ese electorado lo hacía "finalmente": porque no quedaba otra, para que no ganara la derecha, porque... el chantaje, en suma.

Un efecto político de esa situación cómoda fue que, garantizado el voto de los populáricos, la Concertación se puso a la caza de la élite económica. ¿Para garantizar gobernabilidad? Cierto. ¿Por arribismo social? También. ¿Para lucrar, usando un término en boga? Evidentemente, para algunos.

La derecha económica -o el poder económico, a secas- detectó eso de inmediato. La mejor prueba de ello fueron las reseñas sociales de El Mercurio, a partir de 19891990. En vez de dos o tres páginas, se ampliaron a cuatro o cinco, para dar cabida a esas figuras, las del nuevo gobierno que llegaba, que antes estaban fuera de la socialité. Fue divertido, triste, patético y repugnante. Todo junto, o por separado de acuerdo al estado de ánimo con que se miraran esas páginas.

Ese hecho marcó el ingreso de la Concertación al mundo de la élite, un mundo en el que se le adjudicaba un rol de administrador del modelo económico. Lo hicieron, 
fielmente, a cambio de reconocimiento social y el ingreso a los negocios: directorios, sociedades, lobby. La política siempre es buena para aceitar ciertas transacciones.

Sintomáticamente, los más ideologizados de antes, esos izquierdistas, marxistas, revolucionarios, o como quisieran llamarse, que definían quién estaba "con el Pueblo o contra el Pueblo", y eran capaces de no condenarte "por ahora" a muerte, fueron los que más fanáticamente -como ya lo habían hecho antes- abrazaron esa nueva religión, que era la del dinero, los negocios y el poder para imponer sus intereses particulares. ¡Y algunos de esos, ahora, alegan por el lucro en la educación, cuando hicieron de la función pública un lucro!

En el intertanto, la voz de la calle se hacía sorda y las demandas ciudadanas prescindibles. Se congeló la actividad política de las bases, lo que impidió el surgimiento de figuras y la renovación de cuadros, incluso generacionalmente. La Concertación inició el acelerado proceso de envejecimiento que, por falta de presión de abajo, de los jóvenes, ni siquiera fue advertido.

Además, engordaron. Mirarse al espejo también supone reflexionar sobre lo obrado, y quizás algunos cargaban con ciertos remordimientos.

\section{EL CÓMODO BINOMINAL}

Un ejemplo de lo cómoda que terminó siendo la situación fue la permanencia del sistema electoral binominal. Si en un comienzo fue injusto, porque escamoteaba la mayoría, con el tiempo fue útil, porque garantizaba el empate que, a su vez, justificaba las renuncias. Renuncias al programa original, a los discursos de antaño, a las promesas de las campañas electorales -donde sí se recordaba el origen de la Concertación-que, se sabía, no se iban a cumplir y cuyo incumplimiento se iba a justificar por la ausencia de una mayoría significativa producto del binominal. Capicúa.

Con el tiempo, se estableció el empate como realidad, pero, también, como práctica política. El empate era funcional a una transición sin debate y sin osadía. El binominal era justificación y mecanismo práctico.

El problema es que cuando se establece el empate político como escenario perpetuo, ese vacío de poder generado por esa paridad, por la ausencia de un ganador, es llenado por otros. Andrés Allamand una vez habló de los poderes fácticos (después, travesía del desierto mediante, optó por encontrar su lugar entre esos poderes).

En un primer momento, el vacío generado por el empate lo ocupó Pinochet. Tenía a sus senadores designados (personajes oprobiosos, adjetivo que también calza para los después designados en democracia) y la amenaza de la fuerza. Una amenaza ridícula, porque era evidente que no podía usarla. Basta señalar que Estados Unidos no lo habría permitido o lo habría castigado.

Fue una amenaza que, también, fue funcional para la Concertación, porque era otra justificación. Por lo que tuvimos que convivir con una manada de concertacionistas asustadizos, "cagones" -como se diría en "chileno"-, que hacían alharaca de su susto para fundamentar su parálisis. Ejemplos notables: el ejercicio de enlace y el boinazo. 
Luego de ese primer período, el espacio de vacío de poder que generaba el empate del binominal fue ocupado por el que hoy es el verdadero poder: el capital, con sus grupos económicos y sus transnacionales. Desde entonces -mediados del gobierno de Eduardo Frei Ruiz-Tagle-, se hizo claro quién mandaba. Así, vimos empresarios nacionales y extranjeros llegar a La Moneda sin cita previa para ser recibidos, solícitos, por los presidentes. También por la Presidenta.

Y constatamos cómo el Estado se convirtió en una entidad que estaba para facilitar el negocio de los empresarios nacionales y extranjeros (el gobierno asimilado a la figura del mayordomo solícito del patrón), delegando en ellos las decisiones estratégicas del país y continuando con la entrega, iniciada en dictadura, de los recursos naturales.

Ahora que se habla de energía, ¿qué hizo en esta materia el Estado? Simplemente renunciar a toda planificación estratégica, dejando en manos privadas las decisiones de la conformación de la matriz energética del país. O sea, se renunció a la idea de definir las prioridades y actuar de acuerdo al interés general, creyendo que la suma de los intereses particulares de los empresarios conformarían ese interés general. Una versión más refinada del "chorreo" económico. Y tan falsa como aquella.

Con el tiempo, vimos, entonces, gobiernos subordinados al poder del capital. No es solo que financiaran campañas y, después, garantizaran empleo a funcionarios cesantes. También estaba esa fatua seducción por codearse y compartir con el poder real, que estaba y está en los negocios. De ahí a la ostentación de la riqueza no hubo siquiera un paso. Aparecieron políticos que hablaban de sus corbatas de seda italianas y de los vinos que atesoraban. La mala distribución del ingreso persistía, pero ellos, mientras tanto, se aseguraban de estar en el primer decil.

\section{LOS CONVERSOS}

Era, además, inevitable que esa práctica generara a lo menos dos cosas: la convicción por una estrategia económica exactamente como la concebía el poder económico y el buscar el reconocimiento en ese ámbito, que se traducía en acceder a dinero y, consiguientemente, a estatus social.

En la Concertación, también, se vivió una frenética carrera por enriquecerse. No enriquecerse era un fracaso. Y por eso muchos de quienes tuvieron poder armaron verdaderas máquinas de negocios con amigos y parientes. Lo más evidente y rasca: contratar a cercanos en los cargos de que disponen los parlamentarios. Pero hubo figuras más refinadas.

Al final la frontera entre lo público y lo privado se borroneó desde ambos lados. Esa gigantesca área gris que se generó era útil para las dos partes. Esa actitud en las huestes oficialistas fue, además, un golpe definitivo para la política que, reducida en su poder, dejó libre el campo al poder total del dinero. Tanto que, al final, los mayores lobbistas, aparte de los que hicieron de ello una profesión, con oficinas y nombres de fantasía, pasaron a ser los mismos parlamentarios (sin distinción ideológica).

Lo notable es que no hubo resistencia. ¿Por qué? ¿Fue la dureza de la derrota de 1973, para los de izquierda? ¿El mea culpa inconsciente por, en los hechos, haber menospreciado 
las libertades mientras pavimentaban el ideológico camino al poder total? ¿Fue la larga postergación del poder y la riqueza para esos demócratacristianos que estaban convencidos que el Golpe de Estado era cosa pasajera y que a ellos iba a tocarles el mando y sus réditos después de la asonada militar? ¿O simple avaricia, seducción por la plata?

Pesado simbolismo: en un país en que la democracia no redujo la inequidad, esos políticos optaban por refugiarse entre los más ricos e-inequidad mediante-alejarse aún más de la mayoría ciudadana. Lo anterior, cuestionable o no, no era delito. El problema es que, poco a poco, la Concertación fue tolerante con el delito de la corrupción. Ese fue siempre el Talón de Aquiles de la Concertación y no fue capaz -o no quiso- combatirlo.

El mejor ejemplo ha sido la adoración que en la Concertación -y particularmente entre los socialistas- se tiene por Felipe González, el ex jefe de gobierno español. González terminó su período sumido en varios escándalos de corrupción y su gobierno está indisolublemente asociado a los negocios y los negociados. Buena parte del socialismo criollo ha querido -y conseguido- seguirle los pasos. Sin asco y sin vergüenza.

En todo caso, resulta notable cómo los gobiernos de la Concertación pudieron subsistir en ese ejercicio del negocio y esa tolerancia a los negociados corruptos. Porque, aclaremos: no se trató de una gran cantidad de episodios de corrupción, sino de la incapacidad de mostrarse implacables cuando esos hechos salieron a la luz, desacreditando, de paso, a la democracia.

La tolerancia a la corrupción era, además de la degradación de los principios y, por extensión, del ideario democrático, el camino a una inevitable derrota. La sensación de que se estaba en la política para beneficiarse económicamente terminó por generalizarse, aunque se tratara de hechos puntuales (que puntualmente, en todo caso, sumaban y sumaban). ¿Por qué se generalizó esa sensación? Simplemente porque hubo tolerancia a la corrupción, porque nunca se sancionó a los corruptos, porque se les siguió llevando de candidatos, premiándolos con cargos. Con eso bastaba. Y la opinión pública tenía razón. Tolerar hechos de corrupción (o sea, saber de ellos y no condenarlos ni llevarlos a los tribunales) es ser corrupto. No hubo más.

Ese fue el escenario de la derrota de la Concertación en las elecciones presidenciales del 2009. Sebastián Piñera se benefició de una mayoría que no quería más a la Concertación -que había superado el chantaje-, pero que no necesariamente deseaba un gobierno de derecha. Por eso la opinión pública ha sido tan despiadada con la actual administración. Pero, también, por eso esa opinión pública mayoritaria no se identifica con la Concertación, porque a ella ya la rechazó.

\section{¿EL CAMBIO?}

En el actual panorama, a pesar del escenario económico macro favorable-que de poco sirve si no se traduce en beneficios micro, para la gente-, el gobierno debe lidiar con su propia realidad (porque hablar de "fantasmas" es inexacto): estar constituido por funcionarios que provienen del mundo privado empresarial, que siempre han trabajado poniendo por delante su interés particular al interés general; adorar un modelo económico 
que ha fomentado la inequidad; ser amigo de empresarios que, también, hicieron parte de su riqueza por medios discutibles (privatizaciones en dictadura, caso Chispas, etc.); y tener como Presidente de la República a una persona que, en su momento, fue cuestionada, entre otras cosas, por hacer negocios usando información privilegiada.

O sea que la derecha, también, está asociada a la corrupción. Sin embargo, tiene, hoy, una oportunidad: zafar de esa imagen dando ejemplo de probidad y rectitud. Ese solo paso ya la haría meritoria de valores republicanos. ¿Será capaz de hacerlo?

La tarea no se ve fácil por la constitución misma de la derecha. El pasado de muchos de sus dirigentes como funcionarios de la dictadura ya, a estas alturas, importa poco para la opinión pública, aunque sea un hecho de suma importancia. Pero la asociación de la Alianza por Chile con los hombres de los grandes negocios es algo presente. En un país donde el alegato ciudadano puede resumirse en más igualdad, menos discriminación, menos clasismo, mejor distribución, es inevitable que los rencores apunten contra quienes se ven como los beneficiados -y, por qué no, los facilitadores- de esa sociedad desigual. A ellos se les identifica, mayoritariamente, con la derecha.

El actual gobierno debería, entonces, intentar romper con ese lazo de sangre que tiene con el poder económico sin, al mismo tiempo, perder su respaldo, clave para su subsistencia. La pregunta no es si podrá hacerlo, sino si lo desea. Si de verdad aspira a democratizar una sociedad, sabiendo que ello significará que su sector constitutivo perderá poder. En todo caso, ya ha hecho más de lo que muchos esperaban.

A lo anterior debe agregársele otra cosa: la vocación de la derecha por el "orden". En tiempos como los actuales, de demandas y exigencias de participación, la apelación al orden es vista como el intento para restringir los espacios que se abren. Como el mecanismo para acallar las demandas sociales. Como el argumento para desencadenar la represión contra quienes alegan. Es que el orden actual es, en síntesis, opresor e injusto, porque ampara un sistema que ha permitido la injusticia y la desigualdad. Llamar al orden, este orden, es llamar a perpetuar las injusticias.

Inventar un nuevo orden -consensuarlo- es, probablemente, la gran tarea política que ha estado pendiente desde hace años y que nadie ha querido afrontar con la crudeza que exige. Cuando se habla de cambiar el sistema político, probablemente a lo que debiera apuntarse es, más que a pensar en más diputados, a crear mecanismos para transferir más poder a los ciudadanos.

Finalmente, el problema es que la derecha siempre se ha definido como una corriente que defiende e impulsa la libertad, pero eso se ha quedado en simple discurso. Cuando las libertades estuvieron conculcadas por una dictadura, la derecha no tuvo empacho en que se sacrificaran las libertades básicas para obtener beneficios del régimen, entre otras cosas enriqueciéndose. Cuando la ciudadanía hoy reclama más protagonismo, que es una demanda de libertad, el gobierno se enfrenta al dilema de acoger esa exigencia, lo que implica necesariamente ceder cuotas de poder.

¿Será capaz de hacerlo? No, en la medida en que se siga subordinado el interés general a los intereses particulares del poder económico. No, tampoco, si no está dispuesto a romper con muchos de sus amigos que han hecho de combinación política-negocios una forma de enriquecimiento. 
La Concertación fue cooptada por el lobby de ese poder. Fue cooptada, entonces, por los intereses particulares. El actual gobierno, muchos de cuyos integrantes formaron parte de esos intereses particulares, tiene la ventaja de conocer esos mecanismos de cooptación -conocer ese "negocio"- y puede, desde ahí, desde ese conocimiento, rechazar el lobby y poner por sobre los intereses particulares el interés general (a pesar de que su teoría económica dice que la suma de esos intereses particulares redunda, naturalmente, en el interés general).

El gobierno de Piñera puede emprender esa transformación, justamente, desde su relación con esos poderes, porque no es que los conozca, sino que ha sido parte de ellos. Si lo hace, se mostrará, en ese aspecto, más republicano que la Concertación. Y, en los hechos, más preocupado de disolver el poder y, por lo tanto, más democrático.

Puede hacerlo, aunque si lo hace dejará de ser lo que es, lo que no es poco si se analiza su pasado reciente. Esa sí sería la concreción de la promesa del cambio. 